\title{
Effects of Self-efficacy and Self-control on Internet Addiction in Middle School Students: A Social Cognitive Theory-Driven Focus on the Mediating Influence of Social Support
}

\author{
Sun-Yi Yang \\ Assistant Professor, College of Nursing, Konyang University, Daejeon, Korea
}

Purpose: The aim of this study was to investigate internet addiction among middle school students and to examine the mediating effects of social support in the relationships of self-efficacy and self-control with internet addiction. Methods: The participants in the study were 119 middle school students in J city. The measurements included a self-efficacy scale, a self-control scale, a social support scale, and the Internet Addiction Scale for Youth. Data were analyzed using the independent t-test or Mann-Whitney U test, one-way analysis of variance, the Scheffé test, Pearson correlation coefficients, and multiple-regression using SPSS version 22.0. Mediation effects were analyzed by the Sobel test and Baron and Kenny's hierarchical analysis technique. Results: Significant correlations were found among self-efficacy, self-control, and internet addiction. Social support had partial mediating effects in the relationship between self-efficacy and internet addiction, as well as in the relationship between self-control and internet addition. Conclusion: In order to prevent internet addiction, the promotion of interactions among peers, which is a component of social support, is particularly important. It is also necessary to promote face-to-face activities that can strengthen relationships. The findings suggest that intensifying social support may help reduce the level of internet addiction in middle school students.

Key words: Internet; Addictive behavior; Social support; Self efficacy; Self-control

\section{Corresponding author Sun-Yi Yang}

https://orcid.org/0000-0002-7635-4812

College of Nursing, Daejeon Medical Campus, Konyang University, 158 Gwanjeodong-ro, Seo-gu, Daejeon 35365, Korea

TEL +82-42-600-8560 FAX +82-42-600-8555

E-MAIL sunyi@konyang.ac.kr

Received May 28, 2020 Revised Jun 14, 2020 Accepted Jun 30, 2020 (a) This is an Open Access article distributed under the terms of the Creative Commons Attribution NonCommercial License (http://creativecommons.org/licenses/by-nc/4.0/) which permits unrestricted noncommercial use, distribution, and reproduction in any medium, provided the original work is properly cited.

\section{INTRODUCTION}

\section{Need for Study}

According to a survey of internet use by the Ministry of Science and ICT [1], the number of internet users in South Korea is 46.125 million, accounting for $91.5 \%$ of the entire South Korean population, and the rate of internet use among individuals aged 10 19 years is $99.9 \%$ (5.071 million). Concerns about internet addiction are growing in proportion with the convenience and efficiency brought by internet use. In particular, the percentage of middle school students at risk of internet overdependence has steadily increased from 9.7\% in 2016 to $14.3 \%$ in 2019 [2]. A recent study showed that higher academic stress among Korean adolescents intensified their internet addiction [3]. As internet addiction surfaced as a major social problem, the World Health Organization (WHO) included gaming disorder in the International Classification of Diseases, 11th Revision (ICD-11) and officially recognized it as a disease [4]. The WHO emphasized that attention should be paid to online games that can cause neglect of daily activities and changes in physical health, psychological health, and social function [4]. However, with the prolongation of the coronavirus disease 19 
(COVID-19) pandemic in 2020, the online game industry is undergoing an unprecedented boom, and the number of internet and online game users and duration of internet and game use have substantially increased among adolescents, who spend most of their time at home as schools continue to stay closed [5]. Thus, it is necessary to find positive coping measures to prevent internet addiction.

Self-efficacy refers to one's confidence in oneself and the expectation of being capable of performing a certain behavior or activity [6]. A previous study observed a significant negative correlation between self-efficacy and internet addiction among adolescents [7]. Self-control is an ability to control or delay impulses in order to achieve more meaningful and long-term goals [8]. Self-regulatory mechanisms that determine the level of self-control of an individual's behavior may be related to internet addiction, and lack of self-control is one of the main aspects of addiction [9]. A previous study also found a negative correlation between self-control and internet addiction among adolescents [10]. Another meta-analysis observed that intrinsic factors related to the self had a potent impact on internet and gaming addiction [11]. Adolescents may turn to the internet or smartphones, which are easy means of stress relief, when they feel that they cannot resolve a situation on their own or when they are placed in an uncontrollable environment; however, although these means help them temporarily forget the difficulties of reality and serve as an emotional comfort and haven, they eventually intensify adolescents' psychological pain [12].

Social support refers to the tangible and intangible help and protection provided by family, peers, and community, through which individuals receive care, love, empathy, and trust [13]. A previous study reported that low social support contributed to internet gaming addiction among adolescents and that social support was a major predictor of internet addiction [14]. Previous studies observed a negative correlation between social support and internet addiction in adolescents [15]. Çevik and Y1ldiz [14] also stated that adolescents with a low social support system lacked appropriate coping strategies and thus demonstrated a high tendency for internet overuse.

Despite the growing volume of studies on internet addiction, as the topic emerged as a major social problem, most studies have focused on empirical causes of internet addiction, whereas few studies have investigated the theoretical aspects of this phenomenon. Thus, it is necessary to identify the predictors of internet use based on theoretical evidence. The social cognitive theory (SCT) by Bandura [6] explains the causes of behaviors and describes the dynamics of individual, environmental, and behavioral factors that influence behavioral change. Self-efficacy is an individual's willingness to determine whether an individual can perform a specific action, and positive reinforcement through social support is a prerequisite to affecting a behavioral outcome [6]. In a previous study, a mediating role of social support was verified in the relationship between self-efficacy and adherence behavior, although that study did not deal with internet use [16].

Therefore, this study aimed to investigate the impact of self-efficacy and self-control, which are individual factors in the SCT, on internet addiction and the mediating effects of social support as an environmental factor. The results of this study would be useful as foundational data to expand the understanding of the importance of social support and to inform the development of effective measures to address internet use in middle school students.

\section{Purpose}

The aim of this study was to examine the mediating effect of social support in the relationships of self-efficacy and self-control with internet addiction among middle school students, and the specific objectives were as follows:

- To examine the levels of self-efficacy, self-control (cognitive factors), social support (an environmental factor), and internet addiction (a behavioral factor) in middle school students.

- To examine the differences in self-efficacy, self-control, social support, and internet addiction by participants' general characteristics.

- To examine the correlations among self-efficacy, self-control, social support, and internet addiction.

- To examine the mediating effect of social support (an environmental factor) in the effects of self-efficacy and selfcontrol (cognitive factors) on internet addiction (a behavioral factor).

\section{METHODS}

\section{Study Design}

This descriptive research study aimed to examine the mediating effect of social support in the effects of self-efficacy and self-control on internet addiction among middle school students.

\section{Participants}

Data were collected from students at two middle schools in $\mathrm{J}$ city, an island region, after providing an explanation about the purpose of the study and obtaining permission from the school principals. The inclusion criteria were second-year middle school students who were capable of using a smart- 
phone or tablet PC, laptop, or computer and who owned a smartphone or personal computer.

The sample size was determined using $G^{*}$ Power version 3.1.9. With a significance level of $5 \%$ (two-tailed), $95 \%$ power, effect size of .15 (medium), and two predictive factors, the minimum required sample size was 107 . Thus, 120 middle school students were recruited via nonprobability convenience sampling, and after excluding one student (withdrawal rate, $0.8 \%$ ) who did not complete the survey, data from 119 students were included in the final analysis.

\section{Instruments}

\section{1) Self-efficacy}

Self-efficacy was assessed using the Korean version of the General Self-efficacy Scale developed by Lee, Schwarzer, and Jerusalem [17] after obtaining permission from the authors. This tool consists of 10 items. Each item is rated on a 4-point Likert scale from 'strongly disagree' (1) to 'strongly agree' (4). The score ranges from $10 \sim 40$, and a higher score indicates a higher level of self-efficacy. The reliability of the tool as measured with Cronbach's $\alpha$ was .75 at the time of development [17] and .74 in this study.

\section{2) Self-control}

Self-control was assessed using the Korean version of the Brief Self-control Scale, which was adapted by Jo [18] based on the original tool developed by Tangney et al. [8] for use with children and adolescents, after obtaining permission from the author. This 13-item tool consists of two subscales (self-discipline and concentration). Each item is rated on a 5-point Likert scale from 'strongly disagree' (1) to 'strongly agree' (5). The score ranges from 13 to 65 , and a higher score indicates higher self-control. The reliability of the tool as measured with Cronbach's $\alpha$ was .75 at the time of development [18] and .78 in this study.

\section{3) Social support}

Social support was assessed using the Korean version of the Social Support Appraisal Scale, which was adapted by Han and Yoo [19] based on the original tool developed by Dubow and Ullman [20], after obtaining permission from the authors. This 24-item tool consists of three subscales: parent support, peer support, and teacher support. Each item is rated on a 5-point Likert scale from 'strongly disagree'(1) to 'strongly agree'(5). The score ranges from 24 to 120, and a higher score indicates higher social support. The reliability of the tool as measured with Cronbach's $\alpha$ was .92 in a previous study of children [21] and .91 in this study.

\section{4) Internet addiction}

Internet addiction was assessed using the self-diagnostic test of internet addiction developed by the National Information Society Agency [22] for use with adolescents (K-scale). This tool has been made available for public use. This 40-item tool consists of seven subscales: disturbance of adaptive function, disturbance of reality testing, addictive automatic thought, withdrawal, virtual interpersonal relationships, deviant behavior, and tolerance. Each item is rated on a 4-point Likert scale from 'strongly disagree' (1) to 'strongly agree' (4), and scores are classified into general users, potentially at-risk users, and high-risk users according to the internet addiction diagnostic criteria. The criteria for general users are a total score of 94 or lower, a disturbance of adaptive function score of 22 or lower, a withdrawal score of 15 or lower, and a tolerance score of 14 or lower. The criteria for potentially at risk users are a total score of 95 107, a disturbance of adaptive function score of 23 or higher, a withdrawal score of 16 or higher, or a tolerance score of 15 or higher. The criteria for high-risk users are a total score of 108 or higher, a disturbance of adaptive function score of 26 or higher, a withdrawal score of 18 or higher, or a tolerance score of 17 or higher. The reliability of the tool as measured with Cronbach's $\alpha$ was .96 at the time of development [22] and .87 in this study.

\section{Data Collection}

The study was approved by the institutional review board of one university after a review of the purpose, methods, guarantee of participant rights, and questionnaire of the study (2014-0057-3). The participants and their caregivers were informed about the protection of their privacy and confidentiality, voluntary consent, and freedom of withdrawal without any disadvantages. They were informed that they could withdraw from the study at any time, that the questionnaire data would only be used for study purposes, and that anonymity and confidentiality were guaranteed. Students who participated in the questionnaire received certain school supplies.

For data collection, we asked for the cooperation of the principals and school teachers at two middle schools, and the questionnaires were distributed after providing an adequate explanation about the purpose of the study and the methods of completing the questionnaire and consent form. Middle school students who provided written informed consent themselves and obtained consent from their caregivers were instructed to complete the self-reported questionnaire on their own, and it took about 10 15 minutes to complete the questionnaire. 


\section{Data Analysis}

The data were analyzed using SPSS version 22.0 for Windows 2013 (IBM Corp., Armonk, NY, USA). Participants' general characteristics, self-efficacy, self-control, social support, and internet addiction were analyzed in terms of frequency with percentage or mean with standard deviation. Differences in general characteristics, self-efficacy, self-control, social support, and internet addiction were analyzed using the independent $\mathrm{t}$-test or the Mann-Whitney test and one-way analysis of variance followed by the Scheffé post-hoc test. The correlations among self-efficacy, self-control, social support, and internet addiction were analyzed using Pearson correlation coefficients. To identify the predictors of internet addiction, regression analysis was performed with internet addiction as the dependent variable and general characteristics, self-efficacy, and self-control as independent variables. The mediating effect of social support on internet addiction was tested using the hierarchical regression technique presented by Baron and Kenny [23], and the significance of the mediating effect was tested with the Sobel test.

\section{RESULTS}

\section{Participants' Levels of Self-efficacy and Self-control, Social Support, and Internet Addiction}

The mean self-efficacy score among the middle school students was 2.87 out of 4 . The mean self-control score was 2.83 out of 5 . The self-discipline subscale score was 2.81 and the concentration subscale score was 2.87 .

The mean social support score was 3.13 out of 5 . The parent support subscale score was 3.31, the peer support subscale score was 3.30 , and the teacher support subscale score was 2.87 .

The internet addiction score was 2.08 out of 4 . The mean disturbance of adaptive functions score was 2.37 , the disturbance of reality testing score was 1.58 , the addictive automatic thought score was 1.93, the withdrawal score was 2.27, the virtual interpersonal relationship score was 1.76, the deviant behavior score was 1.80 , and the tolerance score was 2.44 (Table 1).

\section{Differences in Self-efficacy, Self-control, Social Support, and Internet Addiction by General Characteristics}

The self-efficacy of the students showed statistically significant differences according to grades $(\mathrm{F}=3.99, p=.021)$, perceived health status $(\mathrm{F}=20.84, p<.001)$, internet user group $(\mathrm{F}=19.38, p<.001)$, and life interference due to internet use $(\mathrm{F}=25.11, p<.001)$. Students with higher grades had higher self-efficacy than those with lower grades. Self-efficacy was higher in those who responded that their perceived health status was good than in those who said that their perceived health was bad. Students who were normal internet users had higher self-efficacy than students who had a potential or high risk for internet addiction. Students who answered that they had no life interference due to internet use had higher self-efficacy than those who stated that they experienced interference at times.

Table 1. Levels of Self-efficacy, Self-control, Social Support, and Internet Addiction

$(N=119)$

\begin{tabular}{|c|c|c|c|c|}
\hline \multirow{2}{*}{ Variables } & Item & Scale & \multirow{2}{*}{ Possible range } & \multirow{2}{*}{ Actual range } \\
\hline & $\mathrm{M} \pm \mathrm{SD}$ & $\mathrm{M} \pm \mathrm{SD}$ & & \\
\hline Self-efficacy & $2.87 \pm 0.54$ & $28.70 \pm 2.69$ & $10 \sim 40$ & $16 \sim 38$ \\
\hline $\begin{array}{l}\text { Self-control } \\
\text { Self-discipline } \\
\text { Concentration }\end{array}$ & $\begin{array}{l}2.83 \pm 0.49 \\
2.81 \pm 0.50 \\
2.87 \pm 0.74\end{array}$ & $\begin{array}{l}36.75 \pm 6.36 \\
25.28 \pm 2.06 \\
11.48 \pm 1.98\end{array}$ & $\begin{array}{r}13 \sim 65 \\
9 \sim 45 \\
4 \sim 20\end{array}$ & $\begin{array}{r}21 \sim 50 \\
16 \sim 38 \\
5 \sim 20\end{array}$ \\
\hline $\begin{array}{l}\text { Social support } \\
\text { Parent support } \\
\text { Peer support } \\
\text { Teacher support }\end{array}$ & $\begin{array}{l}3.13 \pm 0.42 \\
3.31 \pm 0.56 \\
3.30 \pm 0.47 \\
2.87 \pm 0.74\end{array}$ & $\begin{array}{l}75.10 \pm 4.36 \\
26.48 \pm 3.08 \\
26.40 \pm 3.01 \\
22.96 \pm 2.96\end{array}$ & $\begin{array}{c}24 \sim 120 \\
8 \sim 40 \\
8 \sim 40 \\
8 \sim 40\end{array}$ & $\begin{array}{l}24 \sim 114 \\
10 \sim 38 \\
12 \sim 40 \\
10 \sim 39\end{array}$ \\
\hline $\begin{array}{l}\text { Internet addiction } \\
\text { Disturbance of adaptive functions } \\
\text { Disturbance of reality testing } \\
\text { Addictive automatic thought } \\
\text { Withdrawal } \\
\text { Virtual interpersonal relationships } \\
\text { Deviant behavior } \\
\text { Tolerance }\end{array}$ & $\begin{array}{l}2.08 \pm 0.42 \\
2.37 \pm 0.63 \\
1.58 \pm 0.58 \\
1.93 \pm 0.55 \\
2.27 \pm 0.59 \\
1.76 \pm 0.61 \\
1.80 \pm 0.57 \\
2.44 \pm 0.60\end{array}$ & $\begin{array}{r}83.10 \pm 16.90 \\
21.32 \pm 5.64 \\
4.74 \pm 1.73 \\
11.58 \pm 3.32 \\
13.64 \pm 3.52 \\
8.81 \pm 3.04 \\
10.80 \pm 3.45 \\
12.22 \pm 4.02\end{array}$ & $\begin{array}{l}40 \sim 160 \\
9 \sim 36 \\
3 \sim 12 \\
6 \sim 24 \\
6 \sim 24 \\
5 \sim 20 \\
6 \sim 24 \\
5 \sim 20\end{array}$ & $\begin{array}{l}43 \sim 121 \\
9 \sim 33 \\
3 \sim 10 \\
6 \sim 23 \\
6 \sim 23 \\
5 \sim 18 \\
6 \sim 19 \\
5 \sim 19\end{array}$ \\
\hline
\end{tabular}


The self-control of the students showed statistically significant differences according to gender $(\mathrm{t}=3.04, p=.003)$, internet user group $(\mathrm{F}=6.43, p=.002)$, life interference due to internet use $(\mathrm{F}=3.13, p=.047)$, and whether they set limits for internet use time $(\mathrm{t}=2.56, p=.012)$. Male students showed higher self-control than female students. Students who were normal internet users had higher self-control than those who were at a high risk for internet addiction. Students who answered that they had occasionally experienced life interference due to internet use had higher self-control than students who said that they often experienced interference. Students who set limits for internet use time had higher self-control than those who did not.

The social support of the students showed statistically significant differences according to gender $(\mathrm{t}=2.98, p=.004)$, grade $(\mathrm{F}=13.61, p<.001)$, perceived health status $(\mathrm{F}=9.33, p<.001)$, internet user group $(\mathrm{F}=3.18, p=.045)$, and life interference due to internet use $(\mathrm{F}=3.47, p=.034)$. Female students showed higher social support than male students. Students with higher grades had higher social support than those with lower grades. Social support was higher when perceived health status was good than when perceived health status was bad.
Normal internet users had higher social support than those who were high-risk users for internet addiction. Students who replied that they had no life interference due to internet use had higher social support than those who said that they occasionally or often experienced such interference.

Internet addiction showed statistically significant differences according to gender $(\mathrm{t}=2.58, p=.011)$, perceived health status $(\mathrm{F}=21.63, p<.001)$, internet user group $(\mathrm{F}=11.36, p<.001)$, and life interference due to internet use $(\mathrm{F}=21.38, p<.001)$. Male students had significantly higher internet addiction potential than female students. Internet addiction potential was lower among those who perceived their health condition as good than among those who perceived their health condition as neutral or bad. Students who answered that they often experienced life interference due to internet use had higher internet addiction potential than students who said they sometimes or never experienced life interference (Table 2).

\section{Correlations among Internet Addiction, Self-efficacy, Self-control, and Social Support}

Internet addiction was significantly negatively correlated

Table 2. Differences in Self-efficacy, Self-control, Social Support, and Internet Addiction by General Characteristics of Participants

$(N=119)$

\begin{tabular}{|c|c|c|c|c|c|c|c|c|c|c|}
\hline \multirow[b]{2}{*}{ Characteristics } & \multirow[b]{2}{*}{ Categories } & \multirow{2}{*}{$\begin{array}{l}\mathrm{n}(\%) \text { or } \\
\mathrm{M} \pm \mathrm{SD}\end{array}$} & \multicolumn{2}{|c|}{ Self-efficacy } & \multicolumn{2}{|c|}{ Self-control } & \multicolumn{2}{|c|}{ Social support } & \multicolumn{2}{|c|}{ Internet addiction } \\
\hline & & & $\mathrm{M} \pm \mathrm{SD}$ & $\begin{array}{c}t / Z \text { or } F \\
(p)\end{array}$ & $\mathrm{M} \pm \mathrm{SD}$ & $\begin{array}{c}t / Z \text { or } F \\
(p)\end{array}$ & $\mathrm{M} \pm \mathrm{SD}$ & $\begin{array}{c}t / Z \text { or } F \\
(p)\end{array}$ & $\mathrm{M} \pm \mathrm{SD}$ & $\begin{array}{c}t / Z \text { or } F \\
(p)\end{array}$ \\
\hline Mean & & & $2.87 \pm 0.54$ & & $2.83 \pm 0.49$ & & $3.13 \pm 0.42$ & & $2.08 \pm 0.42$ & \\
\hline Gender & $\begin{array}{l}\text { Male } \\
\text { Female }\end{array}$ & $\begin{array}{l}63(52.9) \\
56(47.1)\end{array}$ & $\begin{array}{l}2.71 \pm 0.51 \\
2.63 \pm 0.34\end{array}$ & $\begin{array}{l}1.08 \\
(.282)\end{array}$ & $\begin{array}{l}2.95 \pm 0.47 \\
2.69 \pm 0.48\end{array}$ & $\begin{array}{l}3.04 \\
(.003)\end{array}$ & $\begin{array}{l}3.12 \pm 0.55 \\
3.43 \pm 0.57\end{array}$ & $\begin{array}{c}2.98 \\
(.004)\end{array}$ & $\begin{array}{l}2.17 \pm 0.45 \\
1.97 \pm 0.37\end{array}$ & $\begin{array}{l}2.58 \\
(.011)\end{array}$ \\
\hline Grade & $\begin{array}{l}\text { High } \\
\text { Middle } \\
\text { Low }\end{array}$ & $\begin{array}{l}20(16.8) \\
75(63.0) \\
24(20.2)\end{array}$ & $\begin{array}{l}2.88 \pm 0.61^{\mathrm{a}} \\
2.70 \pm 0.21^{\mathrm{b}} \\
2.60 \pm 0.40^{\mathrm{c}}\end{array}$ & $\begin{array}{l}3.99 \\
(.021) \\
a>c^{*}\end{array}$ & $\begin{array}{l}3.00 \pm 0.33 \\
2.80 \pm 0.54 \\
2.76 \pm 0.39\end{array}$ & $\begin{array}{l}1.66 \\
(.195)\end{array}$ & $\begin{array}{l}3.48 \pm 0.60^{\mathrm{a}} \\
3.37 \pm 0.52^{\mathrm{b}} \\
2.77 \pm 0.46^{\mathrm{c}}\end{array}$ & $\begin{array}{c}3.61 \\
(<.001) \\
a>c^{*}\end{array}$ & $\begin{array}{l}2.06 \pm 0.44 \\
2.05 \pm 0.40 \\
2.18 \pm 0.47\end{array}$ & $\begin{array}{l}0.81 \\
(.450)\end{array}$ \\
\hline $\begin{array}{l}\text { Having close } \\
\text { friends }{ }^{\dagger}\end{array}$ & $\begin{array}{l}\text { Yes } \\
\text { No }\end{array}$ & $\begin{array}{c}117(98.3) \\
2(1.7)\end{array}$ & $\begin{array}{r}117(59.44) \\
2(93.00)\end{array}$ & $\begin{array}{l}1.37 \\
(.172)\end{array}$ & $\begin{array}{r}117(59.91) \\
2(65.25)\end{array}$ & $\begin{array}{l}0.22 \\
(.828)\end{array}$ & $\begin{array}{r}117(59.78) \\
2(73.00)\end{array}$ & $\begin{array}{c}0.54 \\
(.591)\end{array}$ & $\begin{array}{r}117(59.60) \\
2(83.25)\end{array}$ & $\begin{array}{l}0.96 \\
(.336)\end{array}$ \\
\hline $\begin{array}{l}\text { Perceived health } \\
\text { status }\end{array}$ & $\begin{array}{l}\text { Good } \\
\text { Neutral } \\
\text { Bad }\end{array}$ & $\begin{array}{c}50(42.0) \\
60(50.4) \\
9(7.6)\end{array}$ & $\begin{array}{l}3.45 \pm 0.49^{\mathrm{a}} \\
2.65 \pm 0.32^{\mathrm{b}} \\
2.57 \pm 0.43^{\mathrm{c}}\end{array}$ & $\begin{array}{c}20.84 \\
(<.001) \\
a>c^{*}\end{array}$ & $\begin{array}{l}2.81 \pm 0.49 \\
2.79 \pm 0.51 \\
3.12 \pm 0.28\end{array}$ & $\begin{array}{l}1.79 \\
(.172)\end{array}$ & $\begin{array}{l}3.44 \pm 0.61^{\mathrm{a}} \\
3.21 \pm 0.50^{\mathrm{b}} \\
2.62 \pm 0.30^{\mathrm{c}}\end{array}$ & $\begin{array}{c}9.33 \\
(<.001) \\
a>c^{*}\end{array}$ & $\begin{array}{l}1.92 \pm 0.35^{\mathrm{a}} \\
2.10 \pm 0.39^{\mathrm{b}} \\
2.78 \pm 0.20^{\mathrm{c}}\end{array}$ & $\begin{array}{c}1.63 \\
(<.001) \\
c>b, a^{*}\end{array}$ \\
\hline $\begin{array}{l}\text { Internet user } \\
\text { groups }\end{array}$ & $\begin{array}{l}\text { Normal } \\
\text { Potential } \\
\text { High-risk }\end{array}$ & $\begin{array}{l}89(74.8) \\
19(16.0) \\
11(9.2)\end{array}$ & $\begin{array}{l}3.30 \pm 0.56^{\mathrm{a}} \\
2.81 \pm 0.27^{\mathrm{b}} \\
2.57 \pm 0.38^{\mathrm{c}}\end{array}$ & $\begin{array}{c}19.38 \\
(<.001) \\
a>b, c^{*}\end{array}$ & $\begin{array}{l}3.17 \pm 0.40^{\mathrm{a}} \\
2.87 \pm 0.47^{\mathrm{b}} \\
2.75 \pm 0.48^{\mathrm{c}}\end{array}$ & $\begin{array}{l}6.43 \\
(.002) \\
a>c^{*}\end{array}$ & $\begin{array}{l}3.34 \pm 0.60^{\mathrm{a}} \\
3.07 \pm 0.41^{\mathrm{b}} \\
3.00 \pm 0.45^{\mathrm{c}}\end{array}$ & $\begin{array}{l}3.18 \\
(.045) \\
a>c^{*}\end{array}$ & $\begin{array}{l}1.89 \pm 0.30^{\mathrm{a}} \\
2.50 \pm 0.25^{\mathrm{b}} \\
2.88 \pm 0.15^{\mathrm{c}}\end{array}$ & $\begin{array}{c}1.36 \\
(<.001) \\
c>b>a^{*}\end{array}$ \\
\hline $\begin{array}{l}\text { Life interference } \\
\text { due to internet }\end{array}$ & $\begin{array}{l}\text { Never } \\
\text { Sometimes } \\
\text { Often }\end{array}$ & $\begin{array}{l}30(25.2) \\
78(65.6) \\
11(9.2)\end{array}$ & $\begin{array}{l}3.38 \pm 0.54^{\mathrm{a}} \\
2.66 \pm 0.35^{\mathrm{b}} \\
2.46 \pm 0.36^{\mathrm{c}}\end{array}$ & $\begin{array}{c}25.11 \\
(<.001) \\
a>b^{*}\end{array}$ & $\begin{array}{l}2.99 \pm 0.17^{\mathrm{a}} \\
2.87 \pm 0.53^{\mathrm{b}} \\
2.65 \pm 0.39^{\mathrm{c}}\end{array}$ & $\begin{array}{l}3.13 \\
(.047) \\
b>c^{*}\end{array}$ & $\begin{array}{l}3.45 \pm 0.59^{\mathrm{a}} \\
3.24 \pm 0.58^{\mathrm{b}} \\
2.94 \pm 0.29^{\mathrm{c}}\end{array}$ & $\begin{array}{l}3.47 \\
(.034) \\
\mathrm{a}>\mathrm{c}^{*}\end{array}$ & $\begin{array}{l}1.89 \pm 0.28^{\mathrm{a}} \\
2.50 \pm 0.81^{\mathrm{b}} \\
2.88 \pm 0.10^{\mathrm{c}}\end{array}$ & $\begin{array}{c}1.38 \\
(<.001) \\
c>b, a^{*}\end{array}$ \\
\hline $\begin{array}{l}\text { Internet use time } \\
\text { setting }\end{array}$ & $\begin{array}{l}\text { Yes } \\
\text { No }\end{array}$ & $\begin{array}{l}45(37.8) \\
74(62.2)\end{array}$ & $\begin{array}{l}2.63 \pm 0.39 \\
2.71 \pm 0.55\end{array}$ & $\begin{array}{l}0.90 \\
(.371)\end{array}$ & $\begin{array}{l}2.97 \pm 0.51 \\
2.74 \pm 0.46\end{array}$ & $\begin{array}{l}2.56 \\
(.012)\end{array}$ & $\begin{array}{l}3.33 \pm 0.59 \\
3.23 \pm 0.57\end{array}$ & $\begin{array}{c}0.92 \\
(.359)\end{array}$ & $\begin{array}{l}2.07 \pm 0.33 \\
2.09 \pm 0.47\end{array}$ & $\begin{array}{l}0.27 \\
(.785)\end{array}$ \\
\hline $\begin{array}{l}\text { Minutes of internet } \\
\text { use per day }\end{array}$ & $\begin{array}{l}\text { Weekday } \\
\text { Weekend }\end{array}$ & $\begin{array}{l}159.66 \pm 152.48 \\
354.87 \pm 269.96\end{array}$ & & & & & & & & \\
\hline
\end{tabular}

*Scheffé test, $p<.050 ;{ }^{\dagger}$ Mann-Whitney U test. 
with self-efficacy ( $\mathrm{r}=-.49, p<.001)$, self-control $(\mathrm{r}=-.27, p=.004)$, and social support $(\mathrm{r}=-.28, p=.002)$. Regarding the subscales of self-control, internet addiction was significantly negatively correlated with self-discipline $(\mathrm{r}=-.19, p=.043)$ and concentration $(\mathrm{r}=-.35, p<.001)$. Regarding the subscales of social support, internet addiction was significantly negatively correlated with peer support $(\mathrm{r}=-.32, p=.047)$, but was not significantly correlated with family support or teacher support (Table 3).

\section{Mediating Effect of Social Support in the Relation- ships of Self-efficacy and Self-control with Internet Addiction}

To examine the mediating effect of social support in the influence of self-efficacy and self-control on internet addiction in our participants, we performed a three-step regression process [23]. Prior to the analysis, the absence of multicollinearity was confirmed, as tolerance was above the cutoff of 0.1 (at 1.1 1.6) and the variance inflation factors were below 10

Table 3. Correlations among Internet Addiction, Self-efficacy, Selfcontrol, and Social Support

$(N=119)$

\begin{tabular}{lc}
\hline \multirow{2}{*}{ Variables } & \multicolumn{1}{c}{ Internet addiction } \\
\cline { 2 - 2 } & $\mathrm{r}(p)$ \\
\hline Self-efficacy & $-.49(<.001)$ \\
Self-control $\quad-.27(.004)$ \\
$\quad$ Self-discipline & $-.19(.043)$ \\
$\quad$ Concentration & $-.35(<.001)$ \\
Social support & $-.28(.002)$ \\
$\quad$ Parental support & $-.17(.194)$ \\
$\quad$ Peer support & $-.32(.047)$ \\
Teacher support & $-.18(.179)$ \\
\hline
\end{tabular}

(at 1.3 1.8). The normality of the error term was assessed using the Shapiro-Wilk test, and normality was confirmed with a $p$-value of larger than .050 (at .283) [24]. Further, independence of residuals was confirmed with a $d=1.79$ in the DurbinWatson test, thereby confirming the absence of autocorrelation.

The above-described method was used in this study, and the results showed that the independent variable of self-efficacy had a significant effect on the mediating variable (social support) $(\beta=.28, p=.038)$ and the dependent variable (internet addiction) $(\beta=-.49, p<.001)$. The independent variable (self-efficacy) and mediating variable (social support) had a significant effect on the dependent variable (internet addiction) ( $\beta=$ $-.45, p<.001)$. Further, after controlling for the mediating variable (social support), the independent variable (self-efficacy) had a significant effect on the dependent variable (internet addiction), which confirmed that social support had a partial mediating role (Table 4 ).

The other independent variable, self-control, had a significant effect on the mediating variable (social support) $(\beta=.21$, $p=.034$ ) and the dependent variable (internet addiction) ( $\beta=$ $-.28, p=.002)$. The independent variable (self-control) and mediating variable (social support) had a significant effect on the dependent variable (internet addiction) $(\beta=-.29, p=.001)$. Further, after controlling for the mediating variable (social support), the independent variable (self-control) had a significant effect on the dependent variable (internet addiction), which confirmed that social support had a partial mediating role (Table 4). The significance of the mediating effect of social support was examined with the Sobel test, which confirmed the significance of the mediating effects of social support in the relationship between self-efficacy and internet addiction $(Z=-2.73, p=.023)$ and between self-control and internet addiction $(Z=-3.47, p=.037)$ (Figure 1$)$.

Table 4. Mediating Effects of Social Support in the Relationship between Self-efficacy, Self-control, and Internet Addiction ( $N=119)$

\begin{tabular}{|c|c|c|c|c|c|c|c|}
\hline Equations & B & $\beta$ & $\mathrm{t}$ & $p$ & Adj. $\mathrm{R}^{2}$ & $\mathrm{~F}$ & $p$ \\
\hline 1. Self-efficacy $\rightarrow$ social support & 0.40 & .28 & 4.15 & .038 & .12 & 17.25 & .021 \\
\hline 2. Self-efficacy $\rightarrow$ internet addiction & -18.79 & -.49 & 3.92 & $<.001$ & .23 & 36.79 & $<.001$ \\
\hline $\begin{array}{l}\text { 3. Self-efficacy, social support } \rightarrow \text { internet addiction } \\
\text { 1) Self-efficacy } \rightarrow \text { internet addiction } \\
\text { 2) Social support } \rightarrow \text { internet addiction }\end{array}$ & $\begin{array}{r}-17.37 \\
-2.86\end{array}$ & $\begin{array}{l}-.45 \\
-.12\end{array}$ & $\begin{array}{l}5.24 \\
0.24\end{array}$ & $\begin{array}{r}<.001 \\
.042\end{array}$ & .23 & 21.24 & $<.001$ \\
\hline 4. Self-control $\rightarrow$ social support & 0.02 & .21 & 5.19 & .034 & .11 & 17.21 & .031 \\
\hline 5. Self-control $\rightarrow$ internet addiction & -13.23 & -.28 & 3.17 & .002 & .17 & 10.03 & .002 \\
\hline $\begin{array}{l}\text { 6. Self-control, social support } \rightarrow \text { internet addiction } \\
\text { 1) Self-control } \rightarrow \text { internet addiction } \\
\text { 2) Social support } \rightarrow \text { internet addiction }\end{array}$ & $\begin{array}{l}-0.84 \\
-4.71\end{array}$ & $\begin{array}{l}-.29 \\
-.22\end{array}$ & $\begin{array}{l}3.34 \\
3.16\end{array}$ & $\begin{array}{l}.001 \\
.027\end{array}$ & .22 & 15.37 & .022 \\
\hline
\end{tabular}




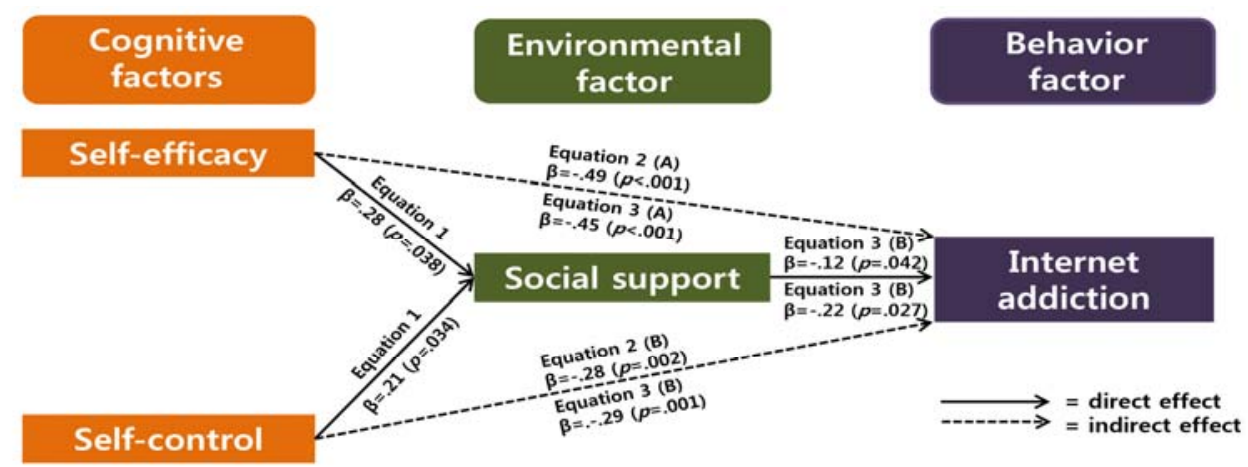

Sobel test: (A) $Z=-2.73, p=.023$; (B) $Z=-3.47, p=.037$

Figure 1. Model showing the influence of self-efficacy and self-control on internet addiction, and the mediating effect of social support.

\section{DISCUSSION}

Adolescence is a transitional period from childhood to adulthood during which adolescents experience major physical and psychological changes and are sensitive to external changes in their environment [25]. This research investigated the mediating effect of social support in the effects of self-efficacy and self-control on internet addiction among middle school students.

First, this study found that there was a significant negative correlation between self-efficacy and internet addiction, and that self-efficacy had a meaningful effect on internet addiction. Prior studies have also confirmed that a higher degree of perceived self-efficacy had a meaningful correlation with internet addiction $[7,26]$, which support the findings of this research. In other words, self-efficacy in middle school students can be a protective factor against internet addiction. Convertsely, another study found that more opportunities for self-expression on the internet or in cyberspace may increase self-efficacy in cyberspace [27]. However, although adolescents' self-efficacy may improve during early stages of internet use when they feel like their interpersonal skills are developing in cyberspace, if they become addicted to the internet, they may feel more isolated in real life, which can worsen interpersonal relations and exacerbate internet addiction [28]. Therefore, it appears to be necessary to explore ways to improve adolescents' self-efficacy and strengthen their interpersonal relations in real life to prevent internet addiction.

Second, this study found a significant negative correlation between self-control and internet addiction, and that self-control had a meaningful effect on internet addiction. Non-addicted internet users were found to have higher self-control than students included in the high-risk group for internet addiction, while self-control in middle school students was also found to have a significant negative correlation with internet addiction. A prior study found a meaningful negative correlation between self-control and internet addiction among adolescents in a city [29], while a recent study also found a meaningful correlation between self-control and internet addiction and confirmed that low self-control tended to lead to internet overuse [30], which supports the findings of the present research. Thus, a lack of self-control serves as a factor that leads to internet addiction. A recent study explained that individuals can undergo behavioral changes if they improve their self-control by setting goals, making plans for themselves, and conducting self-monitoring and self-assessments [30]. This study found that self-control was higher in situations where individuals limited the duration of internet use than in situations without limits, and given these tendencies, it is necessary to take steps to limit the duration of internet use as a way to prevent internet addiction and to strengthen middle school students' self-control. Furthermore, it appears necessary to explore intervention measures that include helping middle school students form their own goals about internet use and conduct self-assessments, as well as suggesting specific self-monitoring methods to help them voluntarily manage their internet use and improve self-control.

Third, this study found that there was a significant negative correlation between social support and internet addiction, and that social support had a meaningful effect on internet addiction. Previous studies have also found significant negative correlations between adolescents' social support and internet addiction [13,15], which support the findings of this research. Male students showed lower social support and higher internet addiction scores than female students, and internet addiction scores were higher among those who perceived their health status as poor than among their counterparts. Thus, it seems to be necessary to determine the reasons for differences in social support according to gender and to seek ways to strengthen social support that reflect the charac- 
teristics of male students as a strategy for internet addiction prevention programs for male students in future studies. In addition, it is necessary to evaluate actual health status in comparison with in comparison with perceived health status, and then to seek alternative activities to promote health in order to strengthen social support and prevent internet addiction.

Fourth, this study demonstrated that social support had a partial mediating influence on self-efficacy and self-control, as well as internet addiction. In other words, self-efficacy and self-control influence social support, and ultimately, one's ability to control internet use. Çevik and Yildız [14] reported that adolescents who received more social support had lower rates of internet addiction and that internet addiction fueled a vicious cycle by diminishing social support and strengthening problematic behavior among adolescents [24]. Thus, it appears that middle school students require social support from peers, family, teachers, and other resources to prevent internet addiction. This research verified a negative correlation between internet addiction and support from peers, who are an important resource for social support, along with family and teachers.

In light of this finding, it is necessary to prevent internet addiction by encouraging students to engage in face-to-face activities with their peers and to strengthen their peer support system. Furthermore, Kwon [25] confirmed that adolescents with high tendencies for internet addiction have the potential to cause problems for their health, schools, families, and even society as a whole, which supports the argument that preliminary protective measures against internet addiction should be developed and implemented. Since this research confirmed that social support has a partial mediating influence on internet addiction, it is necessary to identify and analyze other factors that may influence internet addiction besides social support. Connecting the findings mentioned above, it is expected that forming a strategy to strengthen social support can prevent internet addiction among middle school students with low self-efficacy and self-control.

Drawing conclusions from the discussion above, self-efficacy and self-control are factors that influence internet addiction, while social support partially suppresses internet addiction. This research confirmed that the cognitive factors of self-efficacy and self-control directly influence internet addiction, which is a behavioral factor, but that internet addiction can also be partially reduced by social support, which is an environmental factor. Given these findings, this research is significant in that it empirically demonstrates the need to combine cognitive and environmental factors together to control behavioral factors.

The limitations and future research directions of this study are as follows. First, for convenience, data were collected from students at two middle schools in J city, an island region; thus, the study results have limited generalizability and should be interpreted with caution. In a further study, it is therefore necessary to select students from various regions as study subjects and to conduct repeated studies to compare them with the results of this study. It will also be necessary to re-analyze the causal relationship between the variables through structural equation modeling, which controls for measurement and explanatory errors. Second, a general self-efficacy scale was used rather than a scale measuring internet use-related selfefficacy. Thus, it will be necessary to use a tool that measures internet use-related self-efficacy to analyze these issues more accurately.

\section{CONCLUSION}

The aim of this study was to examine the mediating effect of social support in the relationships of self-efficacy and self-control with internet addiction in middle school students. The results of this study highlight the need for social support to prevent internet addiction. Amid the difficulty of providing faceto-face social support in the current COVID-19 pandemic, other means to provide social support need to be explored in depth. Particularly, as social support given by peers was found to impact middle school students' cognitive and behavioral traits, programs that strengthen peer dynamics should be developed. Subsequent studies should also examine the impact of face-toface and non-face-to-face social support on internet addiction.

\section{Conflict of interest}

No existing or potential conflict of interest relevant to this article was reported.

\section{REFERENCES}

1. Ministry of Science and ICT. 2019 Internet usage survey: Summary report [Internet]. Sejong: Ministry of Science and ICT; 2019 [cited 2020 April 10]. Available from: https://www.msit.go.kr

2. Korean Educational Development Institute. Youth internet · smart phone usage [Internet]. Jincheon: Korean Educational Development Institute; 2019 [cited 2020 April 10]. Available from: https://kess.kedi.re.kr/post/6684806?itemCode=03\&menuId $=\mathrm{m}$ _02_03_03

3. Heo J, Oh J, Subramanian SV, Kim Y, Kawachi I. Addictive internet use among Korean adolescents: A national survey. PLoS One. 2014;9(2):e87819. https://doi.org/10.1371/journal.pone.0087819

4. World Health Organization. Gaming disorder [Internet]. Geneva: World Health Organization; 2018 [cited 2020 June 9]. Available from: https://www.who.int/features/qa/gaming-disorder/en/

5. King DL, Delfabbro PH, Billieux J, Potenza MN. Problematic on- 
line gaming and the COVID-19 pandemic. Journal of Behavioral Addictions. Forthcoming.

https://doi.org/10.1556/2006.2020.00016

6. Bandura A. Human agency in social cognitive theory. The American Psychologist. 1989;44(9):1175-1184.

https://doi.org/10.1037/0003-066x.44.9.1175

7. Oh HJ, Kim YH. Association of self-efficacy and the internet addiction with physical activity in adolescents. Korean Society of Sport Psychology. 2015;26(2):13-25.

https://doi.org/10.14385/KSSP.26.2.13

8. Tangney JP, Baumeister RF, Boone AL. High self-control predicts good adjustment, less pathology, better grades, and interpersonal success. Journal of Personality Homepage. 2004;72(2):271-324. https://doi.org/10.1111/j.0022-3506.2004.00263.x

9. Özdemir Y, Kuzucu Y, Ak S. Depression, loneliness and internet addiction: How important is low self-control? Computers in Human Behavior. 2014;34:284-290.

https://doi.org/10.1016/j.chb.2014.02.009

10. Mei S, Yau YHC, Chai J, Guo J, Potenza MN. Problematic internet use, well-being, self-esteem and self-control: Data from a high school survey in China. Addictive Behaviors. 2016;61:74-79. https://doi.org/10.1016/j.addbeh.2016.05.009

11. Koo HJ, Kwon JH. Risk and protective factors of internet addiction: A meta-analysis of empirical studies in Korea. Yonsei Medical Journal. 2014;55(6):1691-1711.

https://doi.org/10.3349/ymj.2014.55.6.1691

12. Rajab AM, Zaghloul MS, Enabi S, Rajab TM, Al-Khani AM, Basalah A, et al. Gaming addiction and perceived stress among Saudi adolescents. Addictive Behaviors Reports. 2020;11:100261. https://doi.org/10.1016/j.abrep.2020.100261

13. Langford CP, Bowsher J, Maloney JP, Lillis PP. Social support: A conceptual analysis. Journal of Advanced Nursing. 1997;25(1): 95-100. https://doi.org/10.1046/j.1365-2648.1997.1997025095.x

14. Çevik GB, Yıldız MA. The roles of perceived social support, coping, and loneliness in predicting internet addiction in adolescents. Journal of Education and Practice. 2017;8(12):64-73. Available from: https://files.eric.ed.gov/fulltext/EJ1140618.pdf

15. Zhang S, Tian Y, Sui Y, Zhang D, Shi J, Wang P, et al. Relationships between social support, loneliness, and internet addiction in Chinese postsecondary students: A longitudinal cross-lagged analysis. Frontiers in Psychology. 2018;9:1707. https://doi.org/10.3389/fpsyg.2018.01707

16. Martos-Méndez MJ. Self-efficacy and adherence to treatment: The mediating effects of social support. Journal of Behavior, Health and Social Issues. 2015;7(2):19-29. https://doi.org/10.5460/jbhsi.v7.2.52889

17. Lee YM, Schwarzer R, Jerusalem M. Korean adaptation of the general self-efficacy scale [Internet]. Winsor: Authors; 2009 [cited 2020 March 3]. Available from: http://userpage.fu-berlin.de/ health/korean.htm
18. Jo HI. The effect of high school students' perceived time perspective on self-regulated learning: Self-control as a mediator. Journal of Future Oriented Youth Society. 2011;8(2):61-75.

19. Han MH, Yoo AJ. The relation of stress and perceived social support to problem behavior. Korean Journal of Child Studies. 1996; 17(1):173-188

20. Dubow EF, Ullman DG. Assessing social support in elementary school children: The survey of children's social support. Journal of Clinical Child Psychology. 1989;18(1):52-64 https://doi.org/10.1207/s15374424jccp1801_7

21. Hong SP. Effects of social support level on children's self-esteem and subjective well-being. The Journal of Curriculum and Evaluation. 2008;11(2):23-45.

22. National Information Society Agency. K-scale youth self-examination questions and interpretation [Internet]. Seoul: National Information Society Agency; 2007 [cited 2020 March 3]. Available from: https://www.iapc.or.kr/mediaView.do?idx=28\&article_id=ICC ART_0000000000300\&type=A1\#this

23. Baron RM, Kenny DA. The moderator-mediator variable distinction in social psychological research: Conceptual, strategic and statistical considerations. Journal of Personality and Social Psychology. 1986;51(6):1173-1182.

https://doi.org/10.1037//0022-3514.51.6.1173

24. Tabachnick BG, Fidell LS. Using multivariate statistics. 4th ed. Boston: Allyn and Bacon; 2000. p. 67-73.

25. Kwon JH. Verification of a relational model among adolescents' game addiction, social support, and problem behavior. Korea Open Access Journal. 2008;9(2):675-688 https://doi.org/10.15703/kjc.9.2.200806.675

26. Berte DZ, Mahamid FA, Affouneh S. Internet addiction and perceived self-efficacy among university students. International Journal of Mental Health and Addiction. 2019. https://doi.org/10.1007/s11469-019-00160-8

27. Ha JH, Lee HK. The effects of optimism, self-efficacy in the real life, self-efficacy in the cyber-space, hardiness, internet-immersion, on adolescents' internet addiction. The Korea Journal of Counseling. 2005;6(3):919-932.

28. Lee SB, Lee KK, Paik KC, Kim HW, Shin SK. Relationship between internet addiction and anxiety, depression and self efficacy in middle and high school students. Journal of The Korean Neuropsychiatric Association. 2002;40(6):1174-1184.

29. Jeong BI, Park HS. The effects of adolescents' self-control and internet expectation on internet addiction: Focus on moderating effect of parents' raising attitude. Journal of the Korea Society of Computer and Information. 2014;19(3):127-134. https://doi.org/10.9708/jksci.2014.19.3.127

30. Ismail AB, Zawahreh N. Self-control and its relationship with the internet addiction among a sample of Najran university students. Journal of Education and Human Development. 2017;6(2):168-174. https://doi.org/10.15640/jehd.v6n2a18 